Pak. j. sci. ind. res. Ser. B: biol. sci. 201154 (2) 83-87

\title{
Nematicidal Potential of the Galinsoga parviflora
}

\author{
Sadia Ferheen", Musarrat Akhtara, Agha Nisar Ahmed ${ }^{a}$, Muhammad Aijaz Anwar ${ }^{a *}$, \\ Mahboob Ali Kalhoro ${ }^{a}$, Nighat Afza ${ }^{a}$ and Abdul Malik \\ ${ }^{a}$ Pharmaceutical Research Centre, PCSIR Laboratories Complex, Karachi-75280, Pakistan \\ ${ }^{\mathrm{b}}$ HEJ Research Institute of Chemistry, International Centre for Chemical and Biological Sciences, University of \\ Karachi, Karachi-75270, Pakistan
}

(received May 10, 2010; revised December 16, 2010; accepted December 21, 2010)

\begin{abstract}
Seven pure compounds of the Galinsoga parviflora: $\beta$-sitosterol (1); octacosanoic acid (2); ursolic acid (3); 4-hydroxybenzoic acid (4); 3,4-dihydroxybenzoic acid (5); gallic acid (6); $\beta$-sitosterol' 3-O-, $\beta$-D glucopyranoside (7) and the plant crude extract fractions were assayed in the laboratory for their nematicidal properties against plant parasitic nematodes Meloidogyne incognita (root-knot) and Cephalobus litoralis in different concentrations after 24 and $48 \mathrm{~h}$. It was observed that crude extract, hexane, chloroform, ethyl acetate, methanol fractions and compounds no 1, 3, 4, and 7 showed significant activity whereas compounds 2, 5 and 6 showed low order of mortality.
\end{abstract}

Keywords: Galinsoga parviflora, alcoholic extract, Meloidogyne incognita, Cephalobus litoralis, nematicidal activity.

\section{Introduction}

Soil pests viz nematodes, bacteria and fungi play major role in limiting plant growth (Akhtar et al., 1991). Nematodes have been recognized as major constraint in the production of commercially important agricultural crops. Losses to cash crops and vegetables caused by the nematodes in the developed countries are approximately $10.35 \%$. The losses in Asian countries are probably higher due to climatic conditions (Gowen et al., 2007; Maqbool and Shahina et al., 2001; Khan et al., 1989; Gul, 1988). Sufficient work on fanatic studies was done on various crops and it was realized that some specific nematodes are responsible for the losses (Shahid et al., 2007). Root-knot plant parasites and free living soil nematodes were found to be associated with vegetable and fruit plantations (Gowen et al., 2007). Some products have been developed commercially for the control of plant parasitic nematodes, but have not been widely in use because control has tended to be erratic at practical application stage. Much work is still needed in the selection of suitable agents and in the development of production and formulation against nematodes. Most research has been empirical and concerned relatively few organisms and hence there is the need for detailed, quantitative studies on wide range of potential agents with different

*Author for correspondence; E-mail: hirmandriver@gmail.com modes of action (Kerry, 1990). Health and environmental problems, apparently associated with the intensive use of nematicides, have led to removal of several products from the market. (Thomason et al., 1987). However, intensification of cropping has often depended on the use of nematicides and so far no single control measure has proved to be practical and effective. Nematicides have been too expensive for use on most crops in most countries requiring search for development of alternative methods urgently (Pandey et al., 1992). As with the management of insect pests, future nematode control will rely on the integration of several approaches to reduce pesticide use. Nowadays, the most challenging job in tropical and subtropical agriculture is the control of plant parasitic nematodes. The extent of diseases caused by nematodes in agriculture system is far from fully understood. A number of plant extracts, compounds and their derivatives have been reported for their nematicidal activity. Several compounds showed in vitro and in vivo nematicidal activity (Khan et al., 2010; 2008).

The genus Galinsoga belongs to the family Asteraceae that consists of only 3 species, occurring mainly in New Zealand, United Kingdom, Brazil, South Asia and USA. In Pakistan, Galinsoga parviflora is commonly found in Baluchistan, Dir, Hunza, Swat, Gilgat, Murree and Kashmir. The flowers of this plant are pink, white pink or red-tipped ray florets and yellow disk florets 
(Watt et al., 1962). The fruit is with hairy achenes sparsely. Leaves emit pleasant smell when crushed. The plant can grow in semi-shade or moist soil. Roots are useful in treating nettle by rubbing. The juice of the whole plant is applied to treat wounds. It helps to coagulate the blood of fresh cuts and wounds (Watt et al., 1962). In the present study, the nematicidal potential of Galinsoga parviflora was tested in vitro against Meloidogyne incognita and Cephalobus litoralis species. Azadirachta indica extract was taken as conventional nematicide for comparison.

\section{Materials and Methods}

Preparation of plant extracts. The whole plant of Galinsoga parviflora $(20 \mathrm{~kg})$ was collected from Gilgit in December. A voucher specimen (KUH \# 58106) was deposited in the Herbarium of Department of Botany, University of Karachi, Pakistan.

The whole plant of G. parviflora $(20 \mathrm{~kg})$ was dried in a dryer for three days at $50{ }^{\circ} \mathrm{C}$, ground, sieved and soaked in $50 \mathrm{~L}$ ethanol for one week. The ethanolic extract was concentrated to a gummy material that weighed about $500 \mathrm{~g}$.

Fractions. Crude ethanolic extract was further fractionated in hexane, chloroform, ethyl acetate and methanol.

Preparation of nematode Cephalobus litoralis culture. Culture of Cephalobus litoralis which reproduces parthogenetically was prepared using a single egg. Green peas (Pisum sativum) were mashed in small petri dishes. A single egg was carefully picked under stereoscopic binocular and placed beside pea meal paste (PMP) in a petri dish. Nematode eggs hatched within $72 \mathrm{~h}$ and after 10 days, a large number of nematodes in various stages of life cycle was obtained.

Preparation of nematode root-knot culture. Experiments were performed under laboratory conditions at $28^{\circ} \pm 2{ }^{\circ} \mathrm{C}$. Fresh egg masses collected from stock culture maintained on tomato root tissues were kept in water for egg hatching. The larvae emerged after $48 \mathrm{~h}$ from the egg masses incubated at $30^{\circ} \mathrm{C}$ and were used at test species for larval mortality studies. To determine the nematicidal effect of various fractions and pure compounds, freshly hatched second-stage juveniles were placed in tap water. Movements of nematodes were checked by touching them with the needle.
Preparation of substrate for bioassay. Glass tubes, $15 \mathrm{~cm}$ long and $8 \mathrm{~cm}$ dia, were used for the bioassay. Plant extract and compound solutions, 2\%, 1\% and $0.5 \%$, were prepared in water from stock solution and passed through Whatman filter paper No. $1.3 \mathrm{~mL}$ solution was taken in each tube and four tubes were taken for each treatment whereas another four served as the control.

Inoculation. Nematode larvae were isolated through modified Baermann funnel technique using Whatman filter paper No. 41 and counted in a dish in $0.5 \mathrm{~cm}^{2}$ area to determine their concentration. To the tubes containing $3 \mathrm{~mL}$ of $2 \%, 1 \%$ and $0.5 \%$ of plant extract fractions and pure compounds, equal amounts of nematode suspension were added. This brought down the strength of the extract to half i.e. $1 \%, 0.5 \%$ and $0.25 \%$. In another four tubes, distilled water with nematode larvae was taken as control. The experiment was run at room temperature.

Experimental work. Column chromatography was carried out using silica gel of 70-230 mesh and flash chromatography on silica gel 230-400 mesh. Aluminium sheets precoated with silica gel $60 \mathrm{~F}_{254}(20 \times 20 \mathrm{~cm}$, $0.2 \mathrm{~mm}$ thick; E-Merck) were used for TLC to check the purity of the compounds and were visualized under UV light ( 254 and $366 \mathrm{~nm}$ ) followed by ceric sulphate as spraying reagent. Optical rotations were measured on a Jasco DIP-360 digital polarimeter. The UVspectra were recorded on a Hitachi UV-3200 spectrometer $\left(\lambda_{\max }\right.$ in $\mathrm{nm}$ ). IR spectra were recorded on Shimadzu IR-460 spectrophotometer $(\mathrm{v} / \mathrm{cm})$. ElMS, HREIMS, FABMS and HRFABMS spectra were recorded on Jeol JMSHX 110 spectrometer with data system. ${ }^{1} \mathrm{H}$ NMR spectra were recorded on Bruker AMX-400MHz instruments using TMS as an internal reference. The chemical shift values are reported in ppm $(\delta)$ units and the scalar coupling constants $(J)$ are in $\mathrm{Hz}$.

\section{Results and Discussion}

A bioassay guided isolation of the alcoholic extract, hexane, ethyl acetate, chloroform, methanol fractions and pure compounds were subjected for their nematicidal activity at $0.25 \%, 0.5 \%$ and $1 \%$ concentrations in comparison with Azadirachta indica. The structures of pure compounds have been earlier reported (Tariq et al., 2008) through chemical and spectroscopic methods including one dimensional (H-NMR, ${ }^{13} \mathrm{CNMR}$ broad band and DEPT) two dimensional (COSY-45; NOESY, $J$-resolved, hetero COSY) NMR techniques; their structures are shown in Fig. 1. 

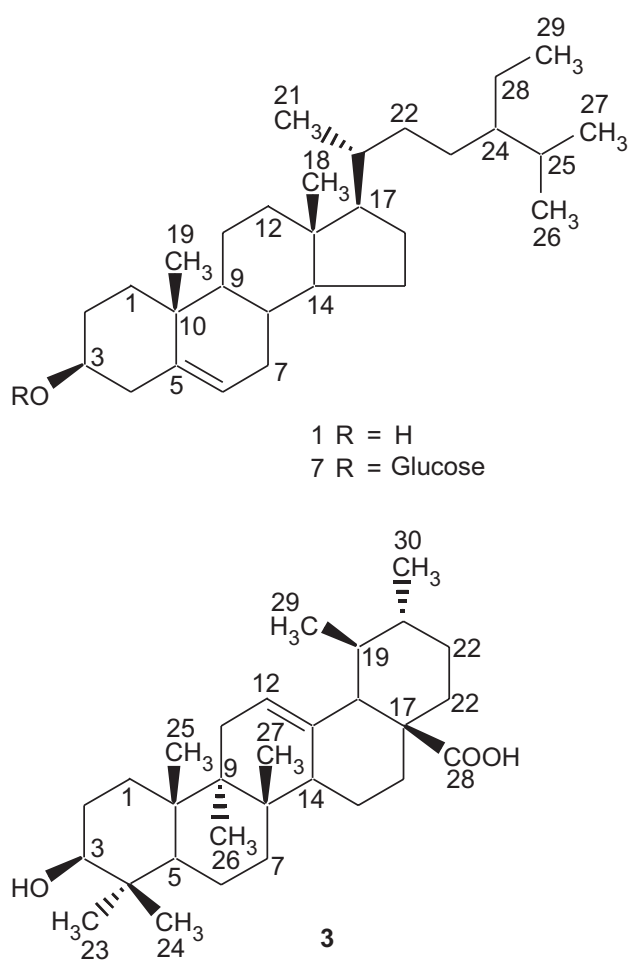

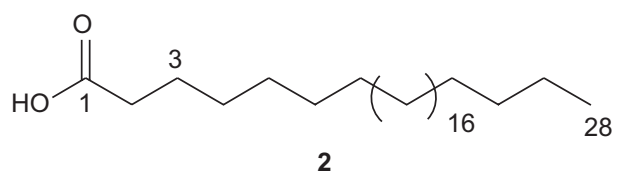

2<smiles>[R]c1cc(C(=O)O)cc([R])c1[R]</smiles>

$4 \mathrm{R}_{1}=\mathrm{H}, \mathrm{R}_{2}=\mathrm{OH}, \mathrm{R}_{3}=\mathrm{H}$
$5 \mathrm{R}_{1}=\mathrm{OH}, \mathrm{R}_{2}=\mathrm{OH}, \mathrm{R}_{3}=\mathrm{H}$
$6 \mathrm{R}_{1}=\mathrm{OH}, \mathrm{R}_{2}=\mathrm{OH}, \mathrm{R}_{3}=\mathrm{OH}$

Fig. 1. Structures of seven compounds isolated from G. parviflora (Tariq et al., 2008).

The nematicidal activity of seven pure compounds of Galinsoga parviflora, its crude ethanolic extract fractions (hexane, ethyl acetate, chloroform, methanol) were tested against Meloidogyne incognita and Cephalobus litoralis. The nematicidal action of the compounds and the fractions against second stage juveniles of both the species are shown in Tables 1-4.

After $24 \mathrm{~h}$, crude extract showed 70\% mortality, hexane fraction $18 \%$, ethyl acetate fraction $70 \%$, chloroform fraction $32 \%$ and methanol fraction $15 \%$ while after $48 \mathrm{~h}$ crude extract showed $80 \%$, hexane fraction $19 \%$, ethyl acetate fraction $90 \%$, chloroform fraction $40 \%$ and methanol fraction, $25 \%$ mortality at the same concentrations against Meloidogyne incognita species. Nematicidal activity of $1 \%, 0.5 \%$, and $0.25 \%$ concentration and control is given in Table 1.

Pure compounds 4, 6, 2 and 1 showed 80\%,75\%,68\% and $60 \%$ mortality, respectively, after $24 \mathrm{~h}$ while after 48 h showed $90 \%, 88 \%, 80 \%, 88 \%, 82 \%, 70 \%$ mortality, respectively. Nematicidal activity of $1,0.5,0.25$ concentrations and the control is given in Table 2 .

One percent of the crude extract, hexane fraction, chloroform fraction, ethyl acetate and methanol soluble fractions showed $70 \%, 30 \%, 15 \%, 35 \%$ and $40 \%$ mortality against Cephalobus litoralis, respectively, after $24 \mathrm{~h}$ and $77 \%, 35 \%, 25 \%, 50 \%$ and $48 \%$ mortality

Table 1. The larval mortality of Meloidogyne incognita (root-knot) nematodes due to extracts

\begin{tabular}{|c|c|c|c|c|c|c|c|c|}
\hline \multirow[t]{3}{*}{ Fractions } & \multicolumn{4}{|c|}{ Concentration of extract } & \multicolumn{4}{|c|}{ Concentration of extract } \\
\hline & $1 \%$ & $0.5 \%$ & $0.25 \%$ & Control & $1 \%$ & $0.5 \%$ & $0.25 \%$ & Control \\
\hline & \multicolumn{4}{|c|}{ Mortality after 24 h (\%) } & \multicolumn{4}{|c|}{ Mortality after $48 \mathrm{~h}(\%)$} \\
\hline Hexane & 18 & 15 & 10 & 1 & 19 & 16 & 10 & 3 \\
\hline Chloroform & 32 & 29 & 22 & 1 & 40 & 30 & 27 & 4 \\
\hline Ethyl acetate & 70 & 48 & 30 & 2 & 90 & 72 & 45 & 5 \\
\hline Methanol & 15 & 12 & 11 & 2 & 25 & 20 & 15 & 3 \\
\hline Crude & 75 & 50 & 32 & 3 & 80 & 68 & 50 & 5 \\
\hline
\end{tabular}


after $48 \mathrm{~h}$, respectively. Nematicidal activity of other concentrations is given in Table 3.

Pure compounds (1-7) isolated from the Galinsoga parviflora were tested for their nematicidal activity on Cephalobus litoralis larvae. The results of in vitro evaluation are shown in Table 4. Compounds 4 (66\%), 3 (65\%), 7 (62\%), 5 (58\%), 6 (55\%), 2 (50\%) and 1 $(45 \%)$ showed mortality (in parentheses) after $24 \mathrm{~h}$ in $1 \%$ concentration while after $48 \mathrm{~h}$, the same compounds showed $70 \%, 70 \%, 70 \%, 68 \%, 62 \%, 60 \%$ and $58 \%$ mortality, respectively, in the same concentration. Nematicidal activity of other concentrations is given in Table 4.

The extracts of neem (Azadirachta indica) are the most suitable in reducing nematode growth in crops and vegetables. Conventional nematicide of neem showed 95\% mortality at the concentration used in the present study. It was noted that ethyl acetate fraction showed

Table 2. The larval mortality of Meloidogyne incognita (root-knot) nematodes due to compounds

\begin{tabular}{|c|c|c|c|c|c|c|c|c|}
\hline \multirow{3}{*}{ Compounds } & \multicolumn{4}{|c|}{ Concentration of compound } & \multicolumn{4}{|c|}{ Concentration of compound } \\
\hline & $1 \%$ & $0.5 \%$ & $0.25 \%$ & Control & $1 \%$ & $0.5 \%$ & $0.25 \%$ & Control \\
\hline & \multicolumn{4}{|c|}{ Mortality after 24 h (\%) } & \multicolumn{4}{|c|}{ Mortality ofter $48 \mathrm{~h}(\%)$} \\
\hline$\beta$-sitosterol (1) & 60 & 48 & 40 & 2 & 70 & 68 & 40 & 4 \\
\hline Octacosanoic acid (2) & 68 & 52 & 30 & 1 & 82 & 57 & 62 & 3 \\
\hline Ursolic acid (3) & 70 & 60 & 52 & 4 & 88 & 70 & 68 & 5 \\
\hline 4-Hydroxybenzoic acid (4) & 81 & 68 & 57 & 2 & 90 & 77 & 60 & 5 \\
\hline 3,4-Dihydroxybenzoic acid (5) & 70 & 62 & 48 & 1 & 80 & 79 & 53 & 3 \\
\hline $\begin{array}{l}\text { Gallic acid (6) } \\
\beta \text {-Sitosterol' 3-O-, } \beta \text {-D }\end{array}$ & 75 & 66 & 50 & 2 & 88 & 72 & 58 & 4 \\
\hline
\end{tabular}

Table 3. The larval mortality of Cephalobus litoralis nematodes due to extracts

\begin{tabular}{|c|c|c|c|c|c|c|c|c|}
\hline \multirow[t]{3}{*}{ Fractions } & \multicolumn{4}{|c|}{ Concentration of extract } & \multicolumn{4}{|c|}{ Concentration of extract } \\
\hline & $1 \%$ & $0.5 \%$ & & Control & \multirow[t]{2}{*}{$1 \%$} & $0.5 \%$ & $0.25 \%$ & Control \\
\hline & \multicolumn{4}{|c|}{ Mortality after $24 \mathrm{~h}(\%)$} & & \multicolumn{3}{|c|}{ Mortality after $48 \mathrm{~h}(\%)$} \\
\hline Hexane & 30 & 17 & 11 & 1 & 35 & 20 & 18 & 2 \\
\hline Chloroform & 15 & 10 & 7 & 2 & 25 & 18 & 15 & 3 \\
\hline Ethyl acetate & 35 & 22 & 14 & 2 & 50 & 30 & 22 & 3 \\
\hline Methanol & 40 & 30 & 22 & 3 & 48 & 33 & 20 & 5 \\
\hline Crude & 70 & 50 & 28 & 4 & 77 & 56 & 37 & 5 \\
\hline
\end{tabular}

Table 4. The larval mortality of Cephalobus litoralis nematodes due to compounds

\begin{tabular}{|c|c|c|c|c|c|c|c|c|}
\hline \multirow[t]{3}{*}{ Compounds } & \multicolumn{4}{|c|}{ Concentration of compound } & \multicolumn{4}{|c|}{ Concentration of compound } \\
\hline & $1 \%$ & 0.5 & 0.2 & Control & $1 \%$ & 0.5 & 0.2 & Control \\
\hline & \multicolumn{4}{|c|}{ Mortality after $24 \mathrm{~h}(\%)$} & \multicolumn{4}{|c|}{ Mortality after $48 \mathrm{~h}(\%)$} \\
\hline$\beta$-Sitosterol (1) & 45 & 38 & 25 & 1 & 58 & 43 & 30 & 2 \\
\hline Octacosanoic acid (2) & 50 & 30 & 16 & 2 & 60 & 38 & 20 & 4 \\
\hline Ursolic acid (3) & 65 & 45 & 34 & 1 & 70 & 50 & 38 & 2 \\
\hline 4-Hydroxybenzoic acid (4) & 66 & 53 & 20 & 1 & 70 & 58 & 30 & 2 \\
\hline 3,4-Dihydroxybenzoic acid (5) & 58 & 34 & 24 & 0 & 68 & 40 & 32 & 1 \\
\hline Gallic acid (6) & 55 & 40 & 27 & 1 & 62 & 50 & 34 & 3 \\
\hline \multicolumn{9}{|l|}{$\beta$-Sitosterol' 3-O-, $\beta$-D } \\
\hline Glucopyranoside (7) & 62 & 53 & 28 & 0 & 70 & 58 & 37 & 2 \\
\hline
\end{tabular}


significant mortality against Meloidogyne incognita in comparison with Cephalobus litoralis species. Compounds $\mathbf{3}$ and $\mathbf{7}$ showed significant mortality against Cephalobus litoralis while pure compound $\mathbf{4}$ showed significant mortality against both the species.

\section{References}

Akhtar, M.A., Haque, M.I., Aslam, M. 1991. Status of phytobacteriology in Pakistan. National Symposium on Status of Plant Pathology in Pakistan, 3-5 Dec., 1991, Department of Botany, University of Karachi, Pakistan (Conference publications).

Gul, A. 1988. Studies on Root-Knot Nematodes (Meloidogyne spp.) in the North West Frontier Province of Pakistan with Special Reference to the Association of $M$. javanica (Treub) Chitwood with Peach [Prunus persica (L.) Batsch]. Ph. D. Thesis, 239 pp., University of Karachi, Pakistan.

Gowen, S.R., Inam ul Haq, M., Sarwar, S.A. 2007. Protective and curative effect of neem (Azadirachta indica) formulations on the development of rootknot nematode, Meloidogyne javanica in roots of tomato plants. Crop Protection, 26: 530-534.

Kerry, B.R. 1990. An assessment of progress toward microbial control of plant parasitic nematodes. Journal of Nematology, 22: 621-631.

Khan, A., Sayed, M., Shaukat, S.S. 2010. Effect of four plant extracts on nematodes associated with mango and its yield. Pakistan Journal of Nematology, 28: 123-127.

Khan, A., Sayed, M., Shaukat, S.S., Handoo, Z.A. 2008. Efficacy of four plant extracts on nematodes associated with papaya in Sindh, Pakistan.
Nematologia Mediterranea, 36: 93-98.

Khan, S.A., Khan, H.A., Saeed, M., Shakir, M.A. 1989. Nematodes associated with nurseries in Karachi. Part II. Croon (Codiaeum variegatum (L.) A.H.L. Juss). Pakistan Journal of Scientific and Industrial Research, 32: 603-607.

Maqbool, M.A., Shahina, F. 2001. Systematic and Distribution: Biodiversity of Nematodes Fauna in Paksitan. National Nematological Research Centre, University of Karachi, Karachi, Pakistan.

Pandey, R., Haseeb, A., Hussain, A. 1992. Distribution, pathogencity and management of Meloidogyne incognita on Mentha arvensis. Afro-Asian Journal of Nematology, 2: 27-34.

Shahid, M., Rehman A.U., Khan, A.U., Mahmood, A. 2007. Geographical distribution and infestation of plant parasitic nematodes on vegetables and fruits in the Punjab province of Pakistan. Pakistan Journal of Nematology, 25: 59-67.

Tariq, S., Ferheen, S., Moazzam, M., Jabbar, A., Riaz, N., Saleem, M., Afza, N., Malik, A., Tareen, R.B. 2008. Phytochemical studies on Galinsoga parviflora. Journal of the Chemical Society of Pakistan, 30: 762-765.

Thomason, I.J. 1987. Challenges facing nematology: Environmental risks with nematicides and the need for new approaches. In: Vistas on Nematology, J.A. Veech and D.W.Dickson (eds.), pp.469-476, Society of Nematologists, Hyattsville, Maryland, USA.

Watt, J.M., Breyer-Brandwijk, M.G. 1962. The Medicinal and Poisonous Plants of Southern and Eastern Africa, 1457 pp., E \& S Livingstone Ltd, London, UK. 